\title{
The effects of $100 \%$ oxygen on breathing pattern are not limited to young children
}

\author{
To the Editor:
}

Breathing $100 \%$ oxygen has been reported to decrease tidal volume $(V \mathrm{~T})$ in infants [1] and recent evidence published in the European Respiratory Journal suggest that transient less pronounced effects are also seen in preschool children [2]. It is unclear whether there is an age dependency beyond infancy in the response to $100 \%$ oxygen or whether it is limited to young children. Here we investigate the effects of $100 \%$ oxygen on breathing pattern across a spectrum of ages to identify the change in $V \mathrm{~T}$ that occurs when subjects breathe $100 \%$ oxygen during a multiple breath nitrogen washout (MBNW) test.

MBNW testing was performed [3] with the Exhalyzer ${ }^{\oplus}$ D using Spiroware 3.1 software (EcoMedics AG, Dürnten, Switzerland). Preschool children were tested using a mask whereas older children and adults used a mouth piece. All trials were re-run through Spiroware 3.2.0 to obtain breath-by-breath output of $V \mathrm{~T}$, respiratory rate $(\mathrm{RR})$ and minute ventilation $\left(V^{\prime} \mathrm{E}\right)$ for all pre-washout and washout breaths. The average $V \mathrm{~T}, \mathrm{RR}$ and $V^{\prime} \mathrm{E}$ of the last 5 breaths of the pre-phase was compared to each washout breath to calculate a relative change in each parameter. We also compared the final 5 breaths of the pre-phase to the average all of breaths collected during the washout phase. A non-linear regression analysis was used to model the breath-by-breath changes. In total data collected from 112 preschool children (50 healthy and 62 with cystic fibrosis (CF)) [4], 18 school age children (all with CF) [5] and 10 adults (all healthy) were include in the analysis. Combined, the subjects ranged from 2.5 years to 29 years of age (median 4.8 years, interquartile range (3.7-17.5)) and $63 \%$ of participants were male.

Exposure to $100 \%$ oxygen resulted in an initial decrease in $V T, R R$ and $V^{\prime} E$ in all three age groups (figure 1), followed by a return to pre-phase levels. This effect was observed in both healthy subjects and those with $\mathrm{CF}$. The average $V \mathrm{~T}$ of the entire washout was not significantly different when compared to the pre-phase in all groups $(0.8 \%$ decrease in healthy preschool children, $3.2 \%$ and $3.9 \%$ decrease in preschool and school age children with CF, respectively, and a $1.6 \%$ decrease in healthy adults).

Our findings are thus consistent with two recent studies that compared the average pre-phase VT to the average $V \mathrm{~T}$ during the washout phase in preschool [2] and school age children [6]. Foong et al. [2] observed a $13 \mathrm{~mL}(4.8 \%)$ decrease in $V$ T whereas JosT et al. [6] observed a $9.7 \mathrm{~mL}(3.5 \%)$ decrease in VT. In infants, breath-by-breath analysis demonstrated temporary hypoventilation driven by a decrease in $V \mathrm{~T}$ after 2-4 breaths, which remained low for 10-25 breaths before returning to baseline [1]. Therefore, changes in tidal breathing in response to exposure to $100 \%$ oxygen observed in infants are not unique to this age group. Rather, they are a phenomena exhibited by subjects of all ages with the magnitude of the effect being small after early infancy. This is important for longitudinal studies with MBNW measurements, as breathing $100 \%$ oxygen is unlikely to affect results.

Courtney Moore ${ }^{1}$, Eric Horton ${ }^{1}$, Nick Benseler ${ }^{1}$, Renee Jensen ${ }^{1}$ and Felix Ratjen ${ }^{1,2,3}$

${ }^{1}$ Translational Medicine, Hospital for Sick Children, Toronto, Canada. ${ }^{2}$ Division of Respiratory Medicine, Hospital for Sick Children, Toronto, Canada. ${ }^{3}$ University of Toronto, Toronto, Canada.

Correspondence: F. Ratjen, Division of Respiratory Medicine, Hospital for Sick Children, 555 University Avenue, Toronto, Ontario, M5G 1X8, Canada. E-mail: felix.ratjen@sickkids.ca

Received: Oct 062017 | Accepted: Oct 112017

@ERSpublications

Changes in tidal breathing in response to $100 \%$ oxygen exposure are exhibited in subjects of all ages http://ow.ly/IZne30gIxLW

Cite this article as: Moore C, Horton E, Benseler N, et al. The effects of $100 \%$ oxygen on breathing pattern are not limited to young children. Eur Respir J 2017; 51: 1702055 [https://doi.org/10.1183/ 13993003.02055-2017]. 

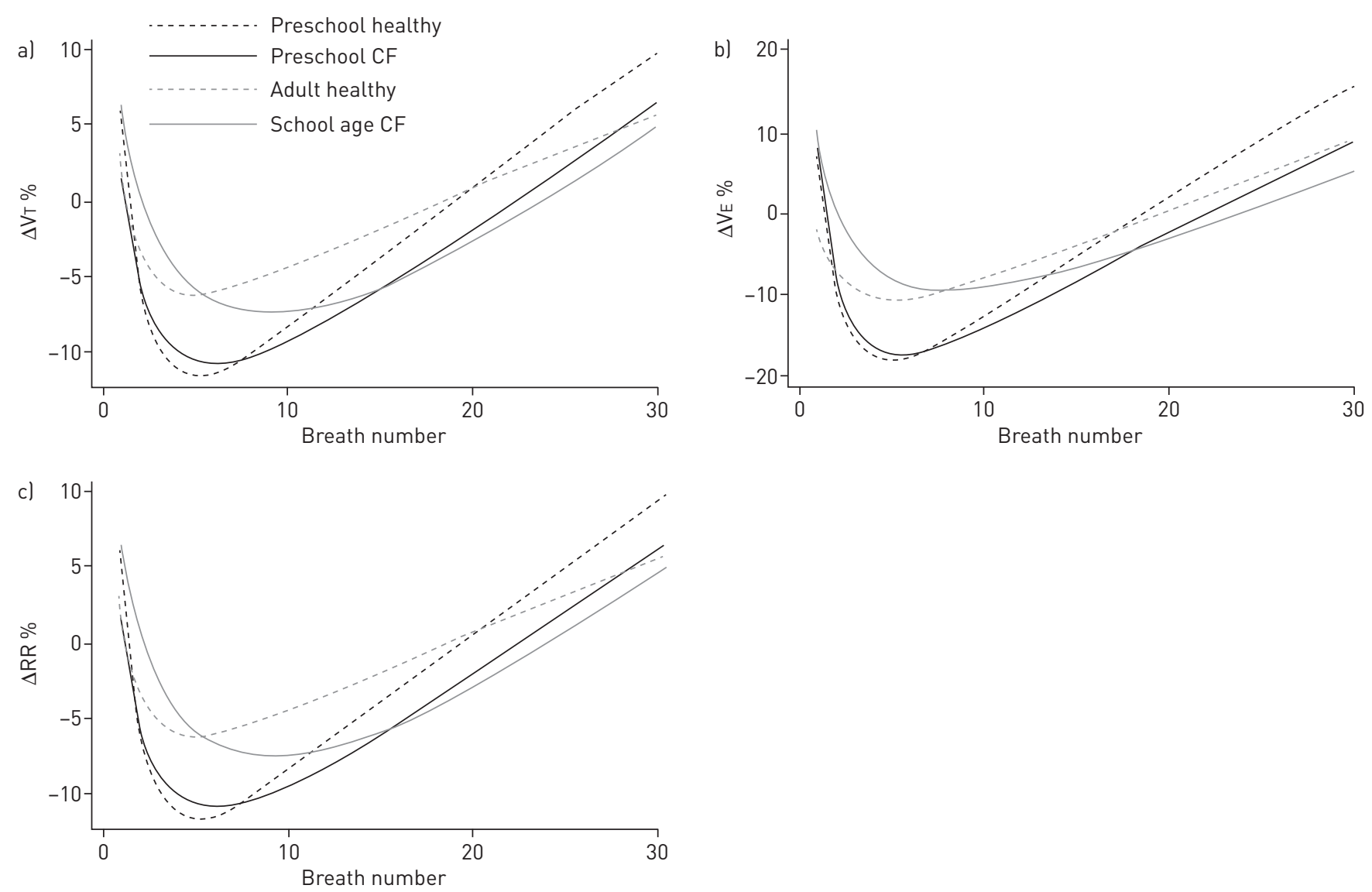

FIGURE 1 Breath-by-breath change in tidal volume $\left(V_{T}\right)(a)$, minute ventilation $\left(V^{\prime} E\right)(b)$ and respiratory rate (RR) (c) relative to the last five breaths of the pre-washout phase

Support statement: Support for this article was provided by the H.E. Sellers Chair in Cystic Fibrosis and the Irwin Family Foundation. Funding information for this article has been deposited with the Crossref Funder Registry

Conflict of interest: Disclosures can be found alongside this article at erj.ersjournals.com

\section{References}

1 Singer F, Yammine S, Schmidt A, et al. Ventilatory response to nitrogen multiple-breath washout in infants. Pediatr Pulmonol 2014; 49: 342-347.

2 Foong RE, Harper AJ, Hall GL, et al. The effect of 100\% oxygen on tidal breathing parameters in preschool children. Eur Respir J 2017; 49: 1601959.

3 Jensen R, Stanojevic S, Gibney K, et al. Multiple breath nitrogen washout: a feasible alternative to mass spectrometry. PloS One 2013; 8: e56868.

4 Stanojevic S, Davis SD, Retsch-Bogart G, et al. Progression of lung disease in preschool patients with cystic fibrosis. Am J Respir Crit Care Med 2017; 195: 1216-1225.

5 Amin R, Stanojevic S, Kane M, et al. A randomized controlled trial to evaluate the lung clearance index as an outcome measure for early phase studies in patients with cystic fibrosis. Respir Med 2016; 112: 59-64.

6 Jost K, Lenherr N, Singer F, et al. Changes in breathing pattern upon 100\% oxygen in children at early school age. Respir Physiol Neurobiol 2016; 228: 9-15. 